\title{
Alizarin Grafting onto Ultrasmall ZnO Nanoparticles: Mode of Binding, Stability, and Colorant Studies
}

\author{
Michel P. de Haan, Naveen Balakrishnan, Andriy R. Kuzmyn, Guanna Li, Hendra M. Willemen, \\ Gunnar Seide, Goverdina C. H. Derksen, Bauke Albada,* and Han Zuilhof*
}

Cite This: Langmuir 2021, 37, 1446-1455

Read Online

\section{ACCESS |}

Џlll Metrics \& More

Article Recommendations

Supporting Information

ABSTRACT: The demand is rising for colorants that are obtained from natural resources, tolerant to industrial processing methods, and meet color quality demands. Herein, we report how relevant properties such as thermal stability and photostability of the natural colorant alizarin can be improved by grafting it onto $\mathrm{ZnO}$ nanoparticles (NPs), allowing application in a warm extrusion process for the fabrication of polyamide fibers. For this study, $\mathrm{ZnO}$ NPs (diameter $2.0 \pm 0.6 \mathrm{~nm}$ ) were synthesized and subsequently functionalized with alizarin. The alizarin-coated $\mathrm{ZnO}$ NPs (i.e., dyed nanoparticles, DNPs) were characterized. Thermogravimetric analysis and ultraviolet-visible (UV-vis) studies revealed that alizarin coating accounts for $\sim 65 \%(\mathrm{w} / \mathrm{w})$ of the total mass of the

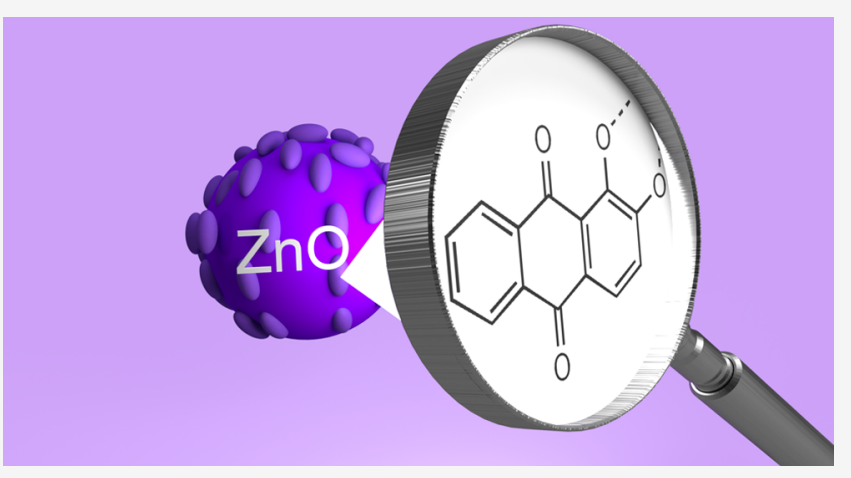
DNPs. A subsequent detailed characterization with Fourier transform infrared (FT-IR), ${ }^{1} \mathrm{H}$ nuclear magnetic resonance (NMR), ${ }^{13} \mathrm{C}$ cross-polarization magic angle spinning (CP-MAS) NMR, X-ray photoelectron spectroscopy (XPS), and quantum chemistry studies using various density functional theory (DFT) functionals and basis sets indicated that binding onto the $\mathrm{ZnO}$ NPs occurred predominantly via the catechol moiety of alizarin. Importantly, this grafting increased the thermal stability of alizarin with $>100{ }^{\circ} \mathrm{C}$, which allowed the processing of the DNPs into polyamide fibers by warm extrusion at $260{ }^{\circ} \mathrm{C}$. Evaluation of the lightfastness of the DNP-dyed nylon fibers revealed that the changes in color quantified via the distance metric $\Delta E^{*}$ of alizarin when embedded in a hybrid material were 2.6 -fold better compared to nylon fibers that were directly dyed with alizarin. This reveals that the process of immobilization of a natural dye onto $\mathrm{ZnO}$ nanoparticles indeed improves the dye properties significantly and opens the way for a wide range of further studies into surfaceimmobilized dyes.

\section{INTRODUCTION}

The application of colorants in materials is not only widely used but the use of organic dyes is closely linked to the dawn of synthetic organic chemistry. ${ }^{1}$ Colorants are applied to materials either via wet (i.e., bath dying of fabric) or solid processing methods (i.e., mixing the colorant with a material in the absence of a solvent). The latter methods are commonly applied to plastics such as polylactic acid, polyamide, poly(ethylene furanoate), and so on. ${ }^{2,3}$ While highly effective and solvent-free, the main disadvantage of solid processing methods is the need for higher temperatures to process the plastics. This puts serious constraints on the thermal stability of the colorant, which is particularly problematic for organic dyes that often display a reduction of their appealing optical properties when exposed to high temperatures. In addition, most organic dyes are fossil-fuel-based and require the use of many toxic reagents during their synthesis. ${ }^{1}$ Naturally occurring dyes do not have this undesired negative environmental impact, although their thermal stability and optical properties hamper their widespread use as colorants for materials. To apply natural dyes as colorants, we explored the immobilization of a dye on benign nanoparticles (NPs) and the effects thereof on its optical properties and thermal stability. Such dyed nanoparticles (DNPs) are of potential interest as a class of colorants, as they can combine the advantages of soluble organic dyes (which are typically easy to process) with those of traditional insoluble pigments (which are typically highly stable). Central in our study is that we would like to probe in detail the molecular aspects of this colorant immobilization.

As a case in point, we selected the natural dye alizarin, a 1,2dihydroxyanthraquinone, also known as Mordant red 11, that can be extracted from the roots of madder. ${ }^{4,5}$ Historically, it

Received: October 13, 2020

Revised: December 14, 2020

Published: January 20, 2021

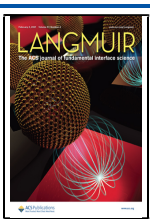


has been used as a colorant in art and clothing, ${ }^{6}$ and more recently in tissue staining, ${ }^{7,8}$ as an organic mediator in sensors for metals, anions, and $\mathrm{pH},{ }^{9}$ and in organic photovoltaics. ${ }^{10}$ The photophysical and chemical properties of alizarin have been studied in depth using theoretical and experimental methods. ${ }^{11-14}$ Furthermore, alizarin grafted onto $\mathrm{TiO}_{2} \mathrm{NPs}$ has been described, ${ }^{15-22}$ revealing that NP immobilization results in hybrid materials with interesting photophysical properties. However, $\mathrm{TiO}_{2}$ has been classified as a group $2 \mathrm{~B}$ carcinogen by the International Agency for Research on Cancer (IARC) in $2010{ }^{23}$ driving the search for alternatives. One of those, $\mathrm{ZnO}$ NPs, does not appear on that list of carcinogens, and thus is receiving a lot of recent attention, e.g., for its changes in optical and antioxidant properties upon hydration, for organic salt adsorption ${ }^{24}$ and with regard to the grafting of organic molecules. ${ }^{25,26}$ Part of this interest also stems from the observation that $\mathrm{ZnO}$ NPs have, compared to $\mathrm{TiO}_{2}$ NPs, a slightly larger band gap, making it less prone to induce photodegradation processes to organics grafted onto the NP surface, although that is, in principle, still feasible, ${ }^{27-30}$ and thus a risk for the current study that we needed to evaluate.

Herein, we report the preparation and characterization of a novel colorant by immobilization of alizarin to small (diameter $\sim 2 \mathrm{~nm}$ ) zinc oxide nanoparticles ( $\mathrm{ZnO}$ NPs) (see Figure 1).

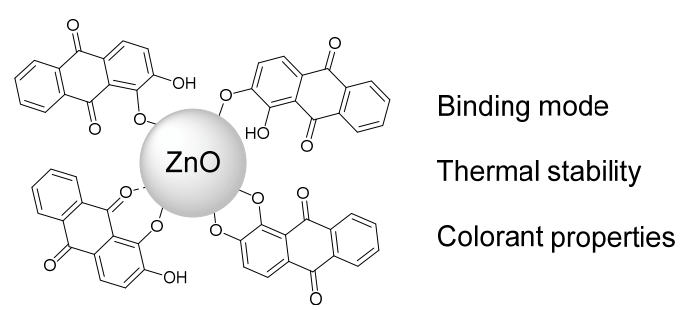

Figure 1. Aim of this study: immobilization of alizarin onto $\mathrm{ZnO}$ nanoparticles, detailed surface characterization, and optimization of stability and colorant properties.

The detailed characterization of the dyed NPs (DNPs) was carried out by ultraviolet-visible (UV-vis) spectroscopy, thermogravimetric analysis (TGA), Fourier transform infrared (FT-IR) spectroscopy, ${ }^{1} \mathrm{H}$ nuclear magnetic resonance (NMR), ${ }^{13} \mathrm{C}$ cross-polarization magic angle spinning (CPMAS) NMR, X-ray photoelectron spectroscopy (XPS), and quantum chemical density functional theory (DFT) studies, to study both the effectiveness of binding and the binding mode of alizarin to $\mathrm{ZnO}$ NPs. Finally, the resulting DNPs were processed into polyamide fibers, and their use as a colorant for synthetic fibers was evaluated using lightfastness tests. We observed that the DNPs displayed a significantly improved thermal stability and photostability compared to the dye itself.

\section{EXPERIMENTAL SECTION}

Chemicals and Materials. All reagents were commercially available and used without further purification. Alizarin (97\% purity), $\mathrm{Zn}(\mathrm{OAc})_{2} \cdot 2 \mathrm{H}_{2} \mathrm{O}$ ( $\geq 98 \%$ purity), $\mathrm{Zn}\left(\mathrm{NO}_{3}\right)_{2} \cdot 6 \mathrm{H}_{2} \mathrm{O}$ (98\% purity), and $\mathrm{ZnO}$ ( $\geq 99 \%$ purity) were purchased from Sigma-Aldrich; $\mathrm{NaOH}$ and toluene were purchased from VWR Chemicals; high-performance liquid chromatography (HPLC)-grade 2-propanol (99.8\% purity) was purchased from Biosolve BV; and Milli-Q water was purified by a Barnstead Water Purification System, with a resistivity of $<18.3 \mathrm{M} \Omega$. $\mathrm{cm}$. Sonication steps were performed in an Elmasonic P $30 \mathrm{H}$ ultrasonic unit at $80 \mathrm{kHz}$. The polyamide Ecopaxx Q130E (polyamide
4,10; melting point, $250^{\circ} \mathrm{C}$; $T_{\mathrm{g}}, 70^{\circ} \mathrm{C}$; density, $1.09 \mathrm{~g} / \mathrm{m}^{3}$ ) was kindly provided by DSM (Geleen, the Netherlands).

Preparation of $\mathrm{ZnO}$ Nanoparticles. A suspension of $\mathrm{ZnO}$ nanoparticles (NPs) was prepared according to the procedure of Bahnemann and Hoffmann. ${ }^{31}$ In this, two mixtures were parallelly prepared in round-bottom flasks equipped with a stirring bar. One mixture contained $246.9 \mathrm{mg}$ of $\mathrm{Zn}(\mathrm{OAc})_{2} \cdot 2 \mathrm{H}_{2} \mathrm{O}(1.125 \mathrm{mmol})$ in 80 $\mathrm{mL}$ of isopropanol; the other mixture contained $8.0 \mathrm{mg}$ of $\mathrm{NaOH}(0.2$ $\mathrm{mmol}$ ) in $8 \mathrm{~mL}$ of isopropanol. Both mixtures were stirred at $55^{\circ} \mathrm{C}$ for $2 \mathrm{~h}$ in closed vessels. Then, the mixture with $\mathrm{Zn}(\mathrm{OAc})_{2}$ was diluted with isopropanol to a volume of $990.4 \mathrm{~mL}$, followed by the addition of $1.6 \mathrm{~mL}$ of Milli-Q water $(88 \mathrm{mmol})$. After cooling to $0{ }^{\circ} \mathrm{C}$ on ice, the mixture containing $\mathrm{NaOH}$ was added. The resulting mixture was stirred at $37^{\circ} \mathrm{C}$ for $2 \mathrm{~h}$ in a closed vessel, yielding a stock solution that contained $0.2 \mathrm{~g}$ of zinc oxide nanoparticle ( $\mathrm{ZnO} \mathrm{NP}$ ) per liter.

Preparation of Alizarin-Grafted ZnO NPs. In a round-bottom flask, $24 \mathrm{mg}(0.1 \mathrm{mmol})$ of alizarin was added to $100 \mathrm{~mL}$ of $0.2 \mathrm{~g} / \mathrm{L}$ $\mathrm{ZnO} \mathrm{NP}$ stock solution, resulting in a pronounced color change for alizarin from brown/yellow to dark purple. The resulting mixture was stirred at RT for $1 \mathrm{~h}$, after which the solvent was evaporated at $40{ }^{\circ} \mathrm{C}$ under reduced pressure. The resulting powder was dispersed in a minimal amount of toluene by sonication and transferred to Eppendorf vials for centrifugation $(13.000 \mathrm{rpm}, 11.000 \mathrm{RCF}, 3$ $\mathrm{min})$. The supernatant was replaced with fresh toluene, and the NPs were dispersed again by vortex mixing for $1 \mathrm{~min}$. This centrifugal washing step was repeated four times, with the final cycle yielding a colorless supernatant. The precipitated DNPs were collected and dried further at $40{ }^{\circ} \mathrm{C}$ under reduced pressure, yielding a dark purple powder. Finally, a curing step was performed by heating the DNPs in a vacuum oven $(<1 \mathrm{mbar})$ at $150{ }^{\circ} \mathrm{C}$ overnight.

Processing of DNPs into Ecopaxx. The polyamide Ecopaxx was dried at $80{ }^{\circ} \mathrm{C}$ overnight, after which compounding was performed using an MC $15 \mathrm{HT}$ twin-screw minicompounder with conical screws from Xplore (Sittard, the Netherlands). The three heating zones of the minicompounder were all set to $260^{\circ} \mathrm{C}$, and compounding was done with $5 \mathrm{~g}$ batches of polyamide Ecopaxx containing $1 \mathrm{wt} \%$ colorant (i.e., the DNPs or alizarin). The extrudate, which was made using a screw speed of $100 \mathrm{rpm}$ and a mixing time of $2 \mathrm{~min}$, was passed through a nozzle with a diameter of $1 \mathrm{~mm}$ and wound. The Ecopaxx alizarin fiber was wound at $30 \mathrm{~m} / \mathrm{min}$, whereas the fiber with DNPs was wound at $25 \mathrm{~m} / \mathrm{min}$ as it had a slightly higher degree of brittleness.

Transmission Electron Microscopy (TEM) of ZnO NPs. The size of the ZnO NPs was determined using a JEM-1400 Plus TEM at $120 \mathrm{kV}$. Samples were prepared by depositing $2 \mu \mathrm{L}$ droplets of $\mathrm{ZnO}$ NP solution on a $32 \mu \mathrm{m}$ hexagon mesh, carbon-coated copper grids. The sample was left to air-dry for $5 \mathrm{~min}$ before insertion for measurement. Reported size averages are based on the values of 3248 $\mathrm{ZnO}$ NPs.

Characterization of Alizarin-Dyed ZnO NPs (DNPs). UV/Vis Spectroscopy. UV/vis measurements were recorded in the 300-700 $\mathrm{nm}$ region on a Cary $50 \mathrm{UV} /$ vis spectrophotometer. A quartz cuvette with a $10 \mathrm{~mm}$ pathlength was used. All samples were dissolved or dispersed in dimethyl sulfoxide (DMSO) unless stated otherwise.

Thermogravimetric Analysis (TGA). TGA measurements (fivefold repetition) were made on a TGA Q500. For all measurements, the following protocol was used: the temperature was increased by $10{ }^{\circ} \mathrm{C} / \mathrm{min}$ under air flow from 20 to $700{ }^{\circ} \mathrm{C}$. The sample quantity was $1-10 \mathrm{mg}$ of compound for each measurement. Data analysis was performed using TA Instruments software (TA Instruments).

Fourier Transform Infrared (FT-IR) Spectroscopy. FT-IR measurements were recorded on a Bruker Tensor 27 FT-IR spectrometer employing a room-temperature deuterated L-alaninedoped triglycine sulfate (RT-DLaTGS) detector. The powder samples were used without further processing by pressing onto a diamond crystal. The samples were measured as a solid powder with 32 scans and a resolution of $4 \mathrm{~cm}^{-1}$. 

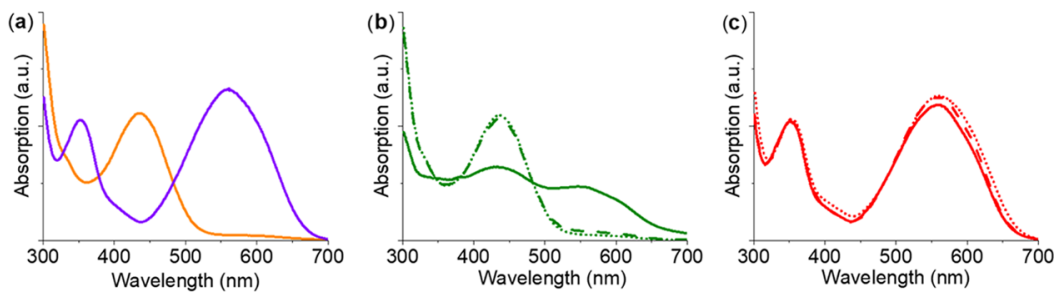

Figure 2. Normalized UV/vis spectra of (a) alizarin (orange line) with alizarin-ZnO DNPs (purple line) and of alizarin in the presence of (b) ZnO and $(\mathrm{c}) \mathrm{Zn}(\mathrm{OAc})_{2}$, with the following ratios: 1:1 (dotted line), 1:10 (dashed line), and 1:100 (solid line). All samples were dissolved in DMSO.
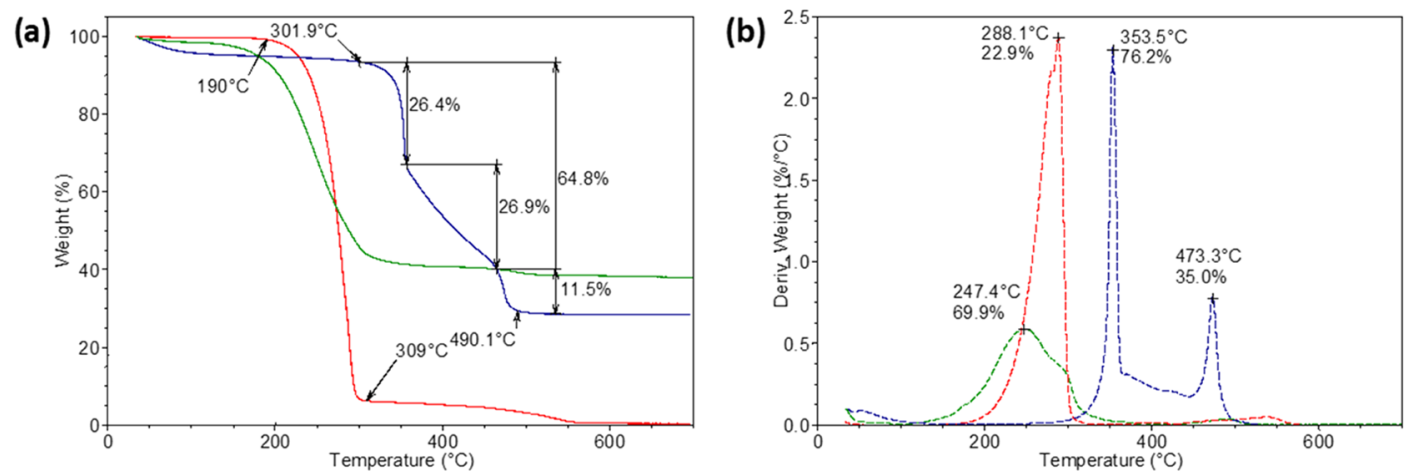

Figure 3. Thermogravimetric analysis curves (a) and their first derivative (b) of alizarin-adsorbed $\mathrm{ZnO}$ NPs (blue), ZnO NPs (green), and alizarin (red) as references.

Quantum Chemical Calculations. Both the isolated alizarin molecule and the alizarin- $\mathrm{ZnO}$ cluster models were optimized using two DFT functionals (B3LYP and MO6, respectively) $)^{32,33}$ and various basis sets $(6-311+\mathrm{G}(\mathrm{d}, \mathrm{p})$ as implemented in the Gaussian 16 suite of programs, ${ }^{34}$ and LanL2TZ+ and def2-TZVPD as obtained from the basis set exchange website www.basissetexchange.org). ${ }^{35,36}$ All stationary points on the potential energy surface were confirmed to be viable minima by vibrational frequency analysis. To rationalize the influence of the coordination environment between alizarin and $\mathrm{Zn}$ on the calculated frequencies, alizarin- $\mathrm{ZnO}$ clusters with one or two $\mathrm{Zn}$ atoms were employed, and various configurations were identified (see the Supporting Information).

Nuclear Magnetic Resonance (NMR). ${ }^{1} \mathrm{H}$ and ${ }^{13} \mathrm{C}$ NMR measurements were recorded on a $400 \mathrm{MHz}$ Bruker Avance III NMR at $298 \mathrm{~K}$. All samples were measured with deuterated dimethyl sulfoxide (DMSO- $d_{6}$ ) as a solvent. Chemical shifts are reported in parts per million ( $\mathrm{ppm})$ and were referenced with respect to the residual DMSO- $d_{6}{ }^{1} \mathrm{H}$ NMR signal $(\delta=2.5 \mathrm{ppm})$.

${ }^{13} \mathrm{C}\left\{{ }^{1} \mathrm{H}\right\}$ cross-polarization magic angle spinning (CP-MAS) NMR spectra were obtained on a $700 \mathrm{MHz}$ Bruker Avance III HD spectrometer. Samples were packed into $4 \mathrm{~mm}$ zirconia rotors. The rotors were spun at an MAS frequency of $14 \mathrm{kHz}$ at $298 \mathrm{~K}$. The ${ }^{13} \mathrm{C}$ CP-MAS spectra were recorded with a recycle delay of $5 \mathrm{~s}$, contact time of $3 \mathrm{~ms}$, and were referenced with respect to adamantane $\left({ }^{13} \mathrm{C}\right.$, $29.456 \mathrm{ppm}$ ).

X-ray Photoelectron Spectroscopy (XPS). XPS measurements were performed using a JPS-9200 photoelectron spectrometer (JEOL Ltd., Japan). All samples were analyzed using a focused monochromated $\mathrm{Al} \mathrm{K} \alpha$ X-ray source (spot size of $300 \mu \mathrm{m}$ ) at constant dwelling times of 50 and $100 \mathrm{~ms}$ for wide scan and narrow scan, respectively, and pass energies of 50 and $10 \mathrm{eV}$ for wide scan and narrow scan, respectively. The power of the $\mathrm{X}$-ray source was $240 \mathrm{~W}$ $(20 \mathrm{~mA}$ and $12 \mathrm{kV})$. The charge compensation was used during the XPS scans with an accelerating voltage of $2.8 \mathrm{eV}$ and a filament current of 4.8 A. XPS wide-scan and narrow-scan spectra were obtained under ultrahigh-vacuum conditions (base pressure, $3 \cdot 10^{-7}$ $\mathrm{Pa}$ ). All narrow-range spectra were corrected with a Shirley background before fitting. Samples were prepared on gold surfaces that were cleaned by sonication in acetone for $5 \mathrm{~min}$, followed by drying with a flow of nitrogen gas. This step was repeated with dichloromethane, ethanol, demineralized water, and, finally, again with ethanol (all analysis grade), to systematically remove organics, dichloromethane, ethanol, and any salts and water, respectively. Next, the surfaces were treated with plasma for $5 \mathrm{~min}$ in a PDC-002 plasma cleaner $\left(100 \mathrm{~W}, 5\right.$ mbar $\mathrm{O}_{2}$; Harrick Scientific Products, Inc.) and subsequently treated by deposition of concentrated samples of alizarin and alizarin-ZnO DNPs in analysis-grade acetone onto those surfaces. The spectra were fitted with symmetrical Gaussian/ Lorentzian (GL(30)) line shapes using CasaXPS (version (2.3.17)). All spectra were referenced to the $\mathrm{C} 1 \mathrm{~s}$ peak attributed to $\mathrm{C}-\mathrm{C}$ and $\mathrm{C}-\mathrm{H}$ atoms at $285.0 \mathrm{eV}$.

Electronic Core-Level Calculations. XPS spectra were simulated using the GAUSSIAN 16 suite of programs, ${ }^{34}$ using the methodology introduced by Giesbers et al. ${ }^{37}$ and Zhao et al. ${ }^{38}$ based on B3LYP/6$311 \mathrm{G}(\mathrm{d}, \mathrm{p})$-optimized geometries and natural bond orbital analysis.

Exposure to UV Light. This was performed in a QUV-weathering tester (Q-Lab Westlake) equipped with UVA340 lamps emitting between 300 and $400 \mathrm{~nm}$ with a maximum at $340 \mathrm{~nm}$. Samples were exposed to $0.68 \mathrm{~W} / \mathrm{m}^{2}$ irradiation at $50{ }^{\circ} \mathrm{C}$, measured at different time points for up to $200 \mathrm{~h}$. CIE- $L^{*} a^{*} b^{*}$ values were measured on a PCECSM 7 colorimeter (PCE Instruments Meschede, Germany), which was calibrated before each data point measurement. Data points were collected as coordinates on three axes: $L^{*}, a^{*}, b^{*}$, of which $L^{*}$ is a measure for lightness ( 0 corresponds to black, 100 corresponds to diffuse white), $a^{*}$ indicates its position on a green-red/magenta axis (values $<0$ correspond to green, values $>0$ correspond to red/ magenta), and $b^{*}$ indicates its position on a blue-yellow axis (values $<0$ correspond to blue, values $>0$ correspond to yellow); changes in $a^{*}$ and $b^{*}$ are related to a change in hue. The data were acquired in SCI mode to determine true color, independent of surface conditions. Samples were measured by means of a $4 \mathrm{~mm}$ aperture size adapter using D65 illumination.

\section{RESULTS AND DISCUSSION}

Synthesis of the Nanoparticles. $\mathrm{ZnO}$ nanoparticles (NPs) were prepared according to literature procedures. ${ }^{31}$ TEM analysis of the NPs revealed a particle size of $2.0 \pm 0.6$ $\mathrm{nm}$ (see Supporting Information Figure S1), which allowed for a high loading of dye per mass unit of NPs, and facilitated 

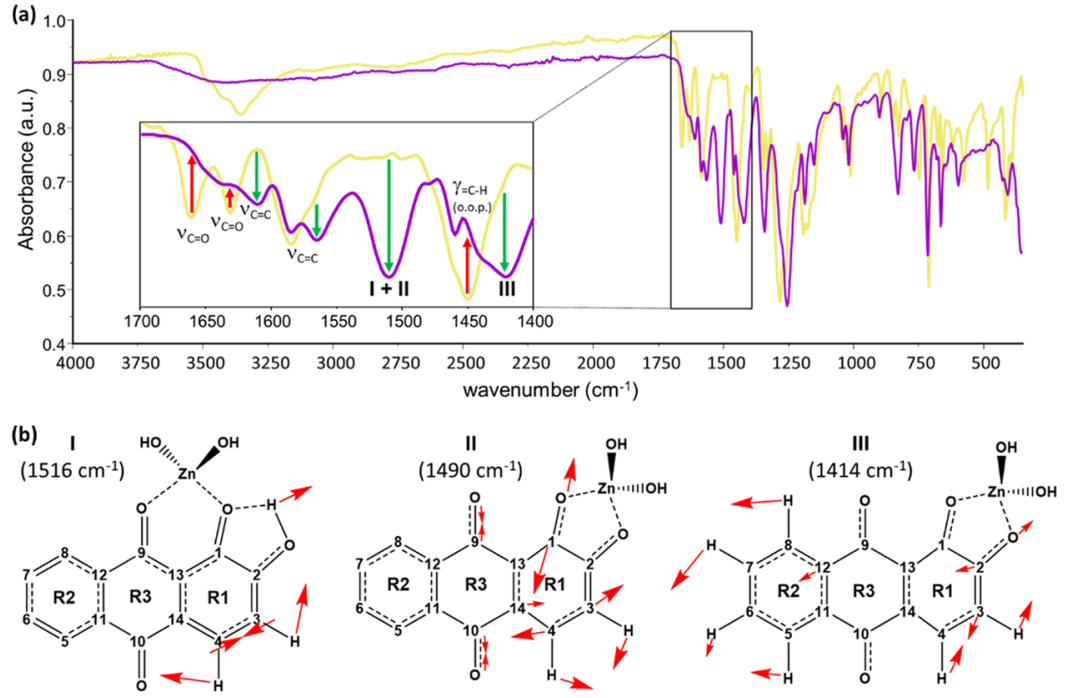

Figure 4. Infrared spectra of alizarin (yellow) and alizarin-ZnO DNPs (purple) (a). The inset depicts the changes in the $1700-1400 \mathrm{~cm}^{-1}$ region. The spectra were normalized to the peak with the strongest intensity; the changes of bands are highlighted with red and green arrows. (b) Complex vibrations that are associated with two structures that are discussed in the text.

analysis of the coating of $\mathrm{ZnO}$ NPs loaded with alizarin by solution-phase ${ }^{1} \mathrm{H}$ NMR, TGA, and XPS.

UV/Vis: Effect of Immobilization of Alizarin on ZnO NPs on the Absorption Spectrum. The UV/vis absorption spectrum of the synthesized DNPs revealed a substantial bathochromic shift of the maximum peak (from 438 to 560 $\mathrm{nm}$ ) and a novel peak at $350 \mathrm{~nm}$ of $\mathrm{ZnO}$-bound alizarin compared to alizarin in DMSO (Figure 2a), as expected from the pronounced visual change from yellow to dark purple. Such a shift and additional absorbance band have been observed by others for alizarin upon increasing the $\mathrm{pH}$ to $9,{ }^{17}$ indicating that $\mathrm{ZnO}$ NP-bound alizarin showed structural features that are similar to deprotonated alizarin. A similar bathochromic shift was observed in the absorption spectra of alizarin in the presence of $\mathrm{ZnO}$ (standard powder) and $\mathrm{Zn}(\mathrm{OAc})_{2}$. Interestingly, although alizarin in the presence of 100 equiv of $\mathrm{ZnO}$ only displayed some of the spectral features that were observed for the DNPs, the presence of only 1 equiv of $\mathrm{Zn}(\mathrm{OAc})_{2}$ was already sufficient to generate spectral features identical to those of the DNPs. Prior to a more detailed elucidation of the binding mode of alizarin by various spectroscopic techniques, we first determined the amount of alizarin that was bound to these $\mathrm{ZnO}$ NPs.

Thermogravimetric Analysis (TGA): Determination of Alizarin Mass Percentage on ZnO NPs and Effect of Immobilization on the Thermal Stability of Alizarin. TGA of the alizarin-coated $\mathrm{ZnO} \mathrm{NPs}$ depicted a stepwise degradation curve from 302 to $490{ }^{\circ} \mathrm{C}$, during which a loss of $64.8 \pm 0.4 \%$ of organic mass was observed (Figure $3 \mathrm{a}$ ). Beyond $500{ }^{\circ} \mathrm{C}$, no additional material was combusted, indicating that this was the remainder of the $\mathrm{ZnO} \mathrm{NP}$ inorganic core. In comparison, alizarin itself displayed a single degradation phase between 190 and $309{ }^{\circ} \mathrm{C}$, followed by a final and complete degradation from 309 to $550{ }^{\circ} \mathrm{C}$ (Figure 3a). This showed that grafting of alizarin on the $\mathrm{ZnO}$ NPs resulted in an improvement in thermal stability above $100{ }^{\circ} \mathrm{C}$. For comparison, the blanc unmodified $\mathrm{ZnO}$ NPs, which still contained the original acetate coating, showed a weight loss of $56 \%$ when heated from 130 to $330{ }^{\circ} \mathrm{C}$. At higher temperatures, only a marginal loss in weight was detected, which also indicates that the $\mathrm{ZnO} \mathrm{NP}$ core is very stable at temperatures up to $700{ }^{\circ} \mathrm{C}$. Since the processing of dyes in textile fibers is typically performed at higher temperatures, we expect that the observed increase in thermal stability from 190 to $300{ }^{\circ} \mathrm{C}$ significantly widens the processing opportunities for this dye.

Fourier Transform Infrared (FT-IR) Spectroscopy: Determination of the Functional Groups Involved in Alizarin Binding. To obtain a better understanding of the interaction between alizarin and the $\mathrm{ZnO}$ NPs, a range of structure determination studies was performed. Pronounced differences were observed between the IR spectra of solid alizarin and the DNPs (Figure 4). The absence of pronounced $\mathrm{O}-\mathrm{H}$ stretching vibrations of the catechol moiety, which are visible for alizarin around $3350 \mathrm{~cm}^{-1}$, suggested binding of alizarin to the $\mathrm{ZnO}$ NPs via deprotonation of both catechol and alcohol functionalities. However, the very broad weak peak between 3700 and $3000 \mathrm{~cm}^{-1}$ could, at this stage, not exclude the presence of some alizarin that is not exclusively bound via the catechol. The region between 1400 and $1700 \mathrm{~cm}^{-1}$ reveals various changes in absorbance bands that provide a more detailed understanding of the interaction between alizarin and the $\mathrm{ZnO}$ NPs. Most notably, a new band emerged at 1510 $\mathrm{cm}^{-1}$ in the spectrum of the DNPs. We analyzed these by DFT calculations using the B3LYP and M06 functionals, and the 6$311+G(d, p)$, LanL2TZ+, and def2-TZVPD basis sets. ${ }^{39}$ The detailed IR spectrum of alizarin (both with respect to relative intensity and peak positions) was-within this set of six methods-best mimicked by the B3LYP/def2-TZVPD combination, which was thus used throughout the rest of these studies. Using such DFT calculations, we were able to assign this $1510 \mathrm{~cm}^{-1}$ band to a complex set of stretching vibrations of an alizarin dianion that is bound to the $\mathrm{ZnO} \mathrm{NP}$ via the catechol moiety (Figure 4b, vibration II; see Supporting Information Table $\mathrm{S} 1$ for a more extensive assignment ${ }^{40-4}$ and Figures S2-S5 for simulated spectra of alizarin and alizarin-ZnO DNPs). Further support of this binding mode comes from a study of the $\mathrm{C}=\mathrm{O}$ stretching vibrations. We observed upon binding to $\mathrm{ZnO}$ a reduction in the intensity of two $\mathrm{C}=\mathrm{O}$ stretching peaks with medium intensity around 1630 and $1660 \mathrm{~cm}^{-1}$, originating from the $C^{9}=O$ and $C^{10}=O$ 


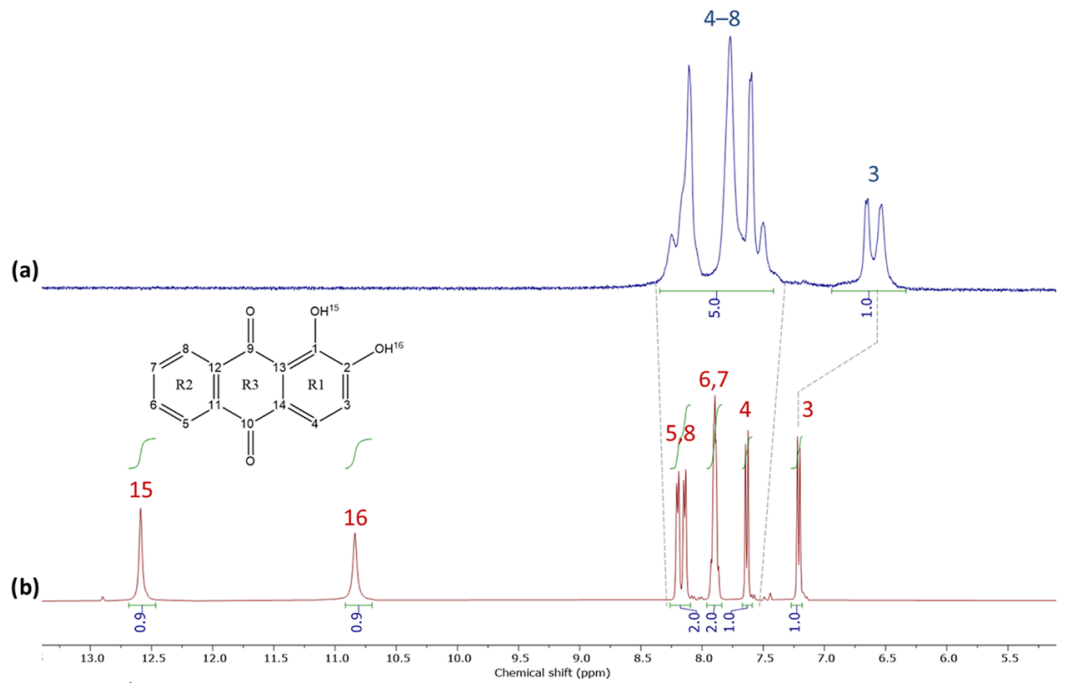

Figure 5. ${ }^{1} \mathrm{H}$ NMR spectrum (400 MHz) of alizarin-ZnO DNPs (a) and alizarin (b) in DMSO- $d_{6}$.

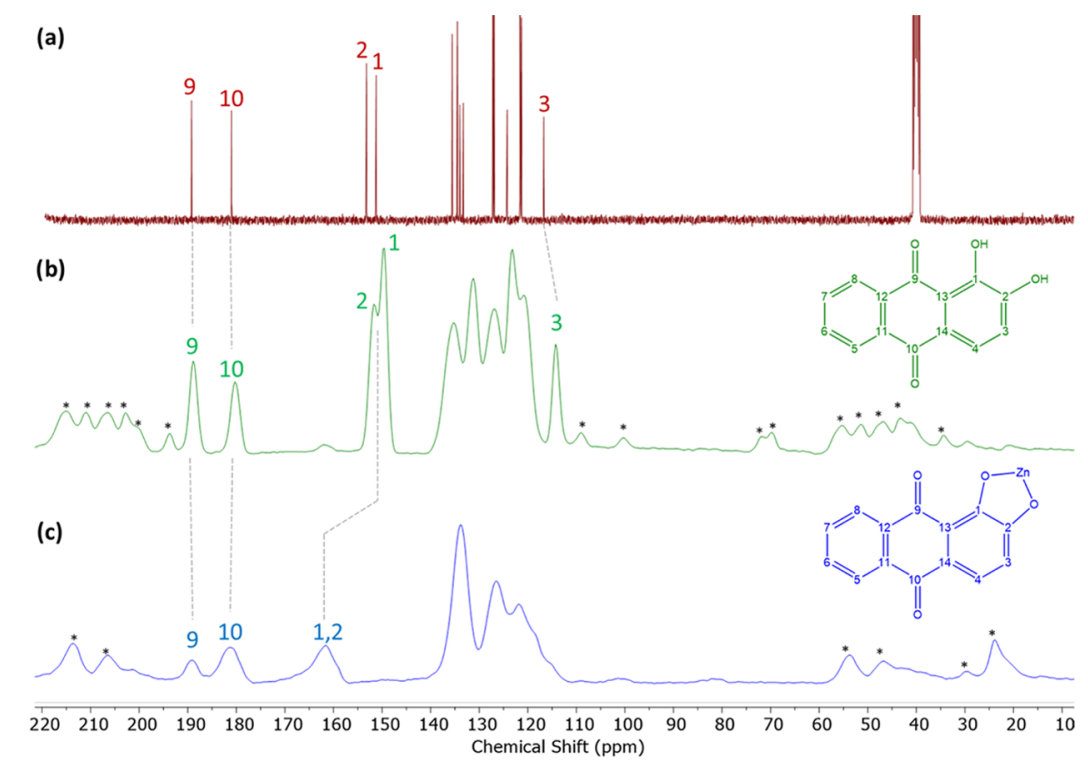

Figure 6. Comparison of the solution-phase ${ }^{13} \mathrm{C}$ NMR (101 MHz) of alizarin (in DMSO- $d_{6}$ ) (a) with the ${ }^{13} \mathrm{C}$ CP-MAS NMR spectra (176 MHz) of alizarin (b), and alizarin-ZnO DNPs (c), all spun at $14 \mathrm{kHz}$. Spinning side bands are denoted with an asterisk. The observed downfield shifting of $\mathrm{C} 1$ and $\mathrm{C} 2$, and the absence of shifting of $\mathrm{C} 9$ and $\mathrm{C} 10$, is indicated with dotted lines.

stretching vibrations, as shown in Figure 4a. We tried to rationalize this by calculating four different binding options: monodentate binding of $\mathrm{Zn}$ to one deprotonated catechol alcohol moiety (and feasible for both $\mathrm{OH}$ groups), bidentate binding of mono-deprotonated alizarin via $\mathrm{C}^{1}-\mathrm{O}^{-}$and $\mathrm{C}^{9}=\mathrm{O}$ to $\mathrm{Zn}$, and binding of $\mathrm{Zn}$ via the two deprotonated catechol alcohol moieties. Only for the latter option, we calculated a decrease in the intensity of the $\mathrm{C}^{10}=\mathrm{O}$ stretching vibration; all other binding options predicted this band to become more intense, in contrast to experiment. In summary, all IR data thus point to a binding mode in which both catechol $-\mathrm{OH}$ moieties are deprotonated and bound to $\mathrm{Zn}$, although additional evidence from other techniques is needed for further confirmation.

${ }^{1} \mathrm{H}$ NMR: Effect of Binding on the Chemical Shifts of Alizarin Hydrogen Atoms. The small size of $2.0 \pm 0.6 \mathrm{~nm}$ diameter of our DNPs allowed solution-phase ${ }^{1} \mathrm{H}$ NMR analysis (Figure 5). ${ }^{48}$ The broadening of all peaks compared to the ${ }^{1} \mathrm{H}$ NMR spectrum of a solution of alizarin itself already indicated the grafting onto $\mathrm{ZnO}$ NPs. The disappearance of the alizarin $\mathrm{O}-\mathrm{H}$ signals, at 12.6 and $10.8 \mathrm{ppm}$, indicates that the catechol moiety was deprotonated due to anchoring of alizarin onto the NP surface, in line with our FT-IR results. We also observed a shift of the hydrogen atom next to the catechol moiety (i.e., $\mathrm{H}^{3}$ ) from 7.2 to $6.6 \mathrm{ppm}$, indicating a significant change in the electron density of the catechol ring as a result of binding of alizarin to the $\mathrm{ZnO}$ NPs via its catechol unit. Since we did observe a small signal at $1.8 \mathrm{ppm}$ (see Supporting Information Figure S6), this could either be assigned to residual acetate left behind by incomplete displacement with alizarin or-as has been suggested previously-by surfacebound $-\mathrm{OH}$ moieties of chemisorbed water. ${ }^{49,50}$ To distinguish between these cases, we prepared DNPs using $\mathrm{ZnO}$ NPs derived from zinc nitrate. Since this material did not contain a signal at $1.8 \mathrm{ppm}$ before grafting of alizarin (see Supporting Information Figure S7), this suggests that after 

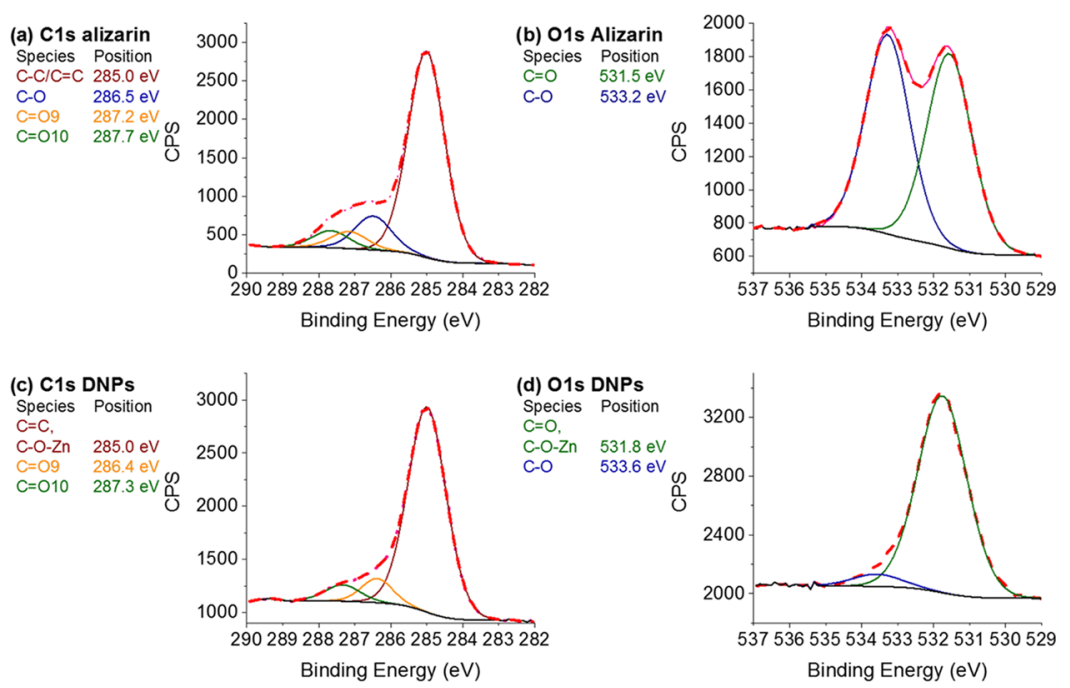

Figure 7. C 1s and O 1s XPS narrow scan of alizarin (a and b, respectively) and alizarin-ZnO DNPs (c and d, respectively).

plasma treatment, there are relatively few surface-bound $\mathrm{Zn}-$ $\mathrm{OH}$ groups on the surface. In addition, upon grafting-in isopropanol that likely contains some water-we did observe this signal at $1.8 \mathrm{ppm}$, indicating that this originated from the grafting process itself.

${ }^{13}$ C CP-MAS NMR: Effect of Binding on the Chemical Shifts of Alizarin Carbon Atoms. To corroborate the results from these solution-phase NMR studies, which confirmed our hypothesis that binding of alizarin was predominantly via the catechol moiety, we applied solid-state NMR techniques to obtain insight into the effects of grafting on the carbon atoms of alizarin. We used cross-polarization magic angle spinning (CP-MAS) to study the effect of immobilization on the chemical shift of the carbon atoms of alizarin (Figure 6). CPMAS NMR was measured at $14 \mathrm{kHz}$ to avoid overlap of side bands originating from 116 to $136 \mathrm{ppm}$ with the carbonyl signals at 181 and $189 \mathrm{ppm}$, and vice versa. For clarity, we compared the liquid-phase ${ }^{13} \mathrm{C}$ NMR spectra of dissolved alizarin (DMSO- $d_{6}$ ) (Figure 6a) with the solid-state NMR spectra of alizarin (Figure 6b) and DNP (Figure 6c). Carbonyl carbon atoms $\mathrm{C} 9$ and $\mathrm{C} 10$ and hydroxyl carbon atoms $\mathrm{C} 1$ and C2 were clearly identified in the CP-MAS NMR, despite their broadening (Figure 6c). In comparison to free alizarin (Figure $6 \mathrm{~b})$, immobilized alizarin experienced a different shielding effect for C1 and C2, as they shift downfield from 150 to 155 ppm in solid alizarin to $160-165$ ppm in ZnO-bound alizarin (Figure 6c). This confirmed our hypothesis that the alizarin was indeed bound by the catechol moiety. Furthermore, no shift was observed for carbonyl carbon atoms $\mathrm{C} 9$ and $\mathrm{C} 1$; in all three spectra, they were found at 181 and $189 \mathrm{ppm}$, indicating that binding of alizarin was not assisted by the carbonyl moieties.

XPS: Evidence of Catechol Binding to the ZnO NPs. Final confirmation of the binding of alizarin to the $\mathrm{ZnO} N P s$ via the catechol moieties was obtained from XPS analysis (Figure $7 \mathrm{a}-\mathrm{d}$, wide-scan spectra are shown in Supporting Information Figures S8 and S9). The C 1s narrow XPS spectra of alizarin showed four main peaks, at $285.0 \mathrm{eV}[\underline{\mathrm{C}}-\mathrm{C} / \mathrm{H}]$, $286.5 \mathrm{eV}[\underline{\mathbf{C}}-\mathrm{O}], 287.2 \mathrm{eV}[\underline{\mathbf{C}}=\mathrm{O}(9)]$, and $287.7 \mathrm{eV}[\mathbf{C}=$ $\mathrm{O}(10)]$, respectively (Figure $7 \mathrm{a}$ ). The intensity ratio of $[\underline{\mathbf{C}}-\mathrm{C} /$ $\mathrm{H}]:[\underline{\mathbf{C}}-\mathrm{OH}]:[\underline{\mathbf{C}}=\mathrm{O}]:[\underline{\mathbf{C}}=\mathrm{O}]$ was experimentally determined to be 10.5:1.7:0.9:0.9, indicating that the chemical natures of
$[\underline{\mathbf{C}}=\mathrm{O}(9)]$ and $[\underline{\mathbf{C}}=\mathrm{O}(10)]$ were discernably different, probably due to intramolecular hydrogen bonding of $\mathrm{C}=$ $\mathrm{O}(9)$ to the neighboring catechol moiety. The deconvoluted spectra were in accordance with the molecular structure of alizarin, as we find, for example, the 2:1:1 intensity for the three peaks of the oxygen-bound carbon atoms, while this had not been found in previous analyses of alizarin, which only yielded a $\underline{\mathbf{C}}=\mathrm{O} / \underline{\mathbf{C}}-\mathrm{O}$ ratio of $1: 2.3$, rather than $1: 1 .^{51}$ The $\mathrm{C}=\mathrm{O} / \mathrm{C}-\mathrm{O}$ ratio is not affected by the $\pi^{*} \leftarrow \pi$ shakeup satellites since those features are typically present at higher than $290 \mathrm{eV}$ energy ranges. We also observed these shakeup satellites at 290.5 and $292.3 \mathrm{eV}$, as shown in Figure S10. ${ }^{52} \mathrm{In}$ addition, our assignment concurs with that of B3LYP/6$311+\mathrm{G}(\mathrm{d}, \mathrm{p})$-based XP spectrum simulations, ${ }^{37,38}$ which yielded peaks at $285.7,287.8,288.1$, and $288.5 \mathrm{eV}$, with a ratio of $10: 2: 1: 1 .^{38}$ In this, it should be noted that shifting the main peak of alizarin to $285.0 \mathrm{eV}$, as is standard for aliphatic chains, may not be fully correct for this aromatic system with only $\mathrm{sp}^{2}$-hybridized carbon atoms. If this would shift the main peak by $0.7 \mathrm{eV}$, then this would yield a near-perfect agreement between experiment and theory.

The deconvoluted $\mathrm{C}$ 1s narrow-scan spectrum of DNPs showed three main peaks, at $285.0 \mathrm{eV}[\mathrm{C}-\mathrm{C} / \mathrm{OZn}], 286.4 \mathrm{eV}$ $[\underline{\mathbf{C}}=\mathrm{O}(\mathrm{C} 9+\mathrm{C} 10)]$, and $287.3 \mathrm{eV}[\underline{\mathbf{C}}-\mathrm{O}(\mathrm{C} 1+\mathrm{C} 2)]$, in a 12.0:1.1:0.8 ratio (Figure $7 \mathrm{c}$ ), which is thus marked by a significant shift to higher binding energies for the catechol carbon atoms upon $\mathrm{Zn}$ binding, in line with the computed values of $286.4(\underline{\mathbf{C}}-\mathrm{C}), 288.8(\underline{\mathbf{C}}=\mathrm{O})$, and $289.1(\underline{\mathbf{C}}-\mathrm{O}) \mathrm{eV}$, respectively.

The deconvoluted $\mathrm{O}$ 1s narrow-scan spectrum of alizarin showed two signals of similar intensity at 531.5 and $533.2 \mathrm{eV}$ (Figure $7 \mathrm{~b}$ ), corresponding to the two carbonyl $\mathrm{O}$ atoms and the two catechol $\mathrm{O}$ atoms. This can be fitted by B3LYP/6$311+\mathrm{G}(\mathrm{d}, \mathrm{p})$-based simulations using the relation: $E_{\exp }=E_{\text {calc }}+$ $\mathrm{A}$ (all in $\mathrm{eV}$ ), as done for $\mathrm{C}$ and $\mathrm{N}$ atoms, ${ }^{38}$ which would yield $\mathrm{A}=17.7 \mathrm{eV}$. Such a fit yields 530.8 and $531.8 \mathrm{eV}$ for the carbonyl carbon atoms $\mathrm{C} 9$ and $\mathrm{C} 10$, respectively, and 533.4 and $533.6 \mathrm{eV}$ for the alcohol moieties $\mathrm{C} 1$ and $\mathrm{C} 2$, respectively. The experimental $\mathrm{O}$ 1s narrow-scan spectrum of the DNPs showed only one major signal at $531.8 \mathrm{eV}$, with just a minor signal at $533.6 \mathrm{eV}$ (in a 1:0.05 ratio; Figure $7 \mathrm{~d}$ ). The B3LYP/ $6-311+G(d, p)$-based simulations yield binding energies of 

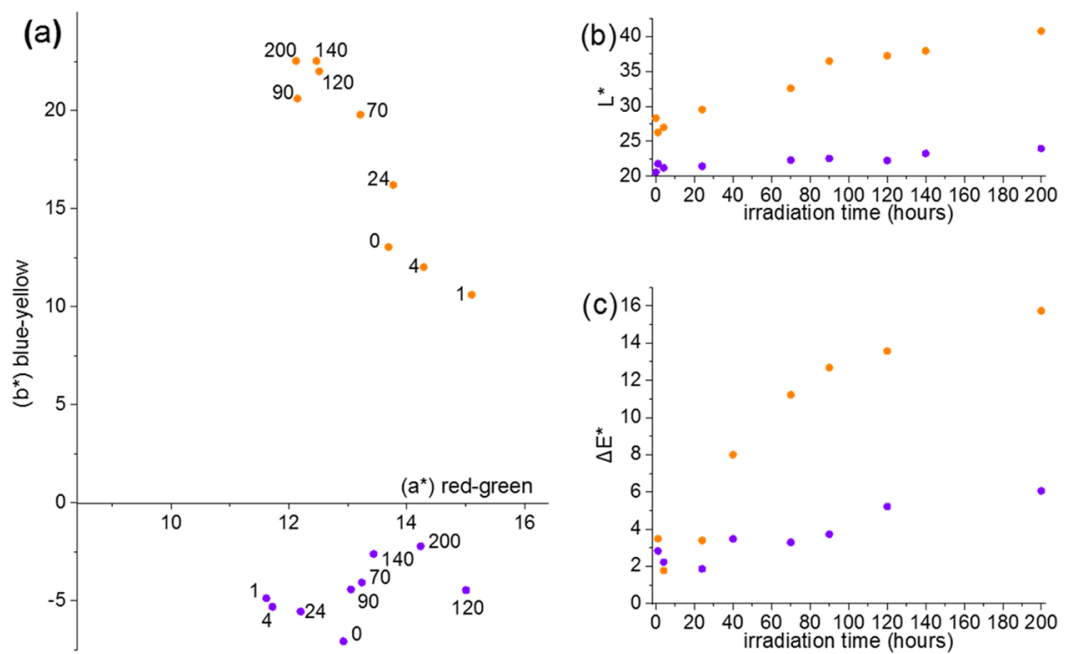

Figure 8. Lightfastness test of alizarin and alizarin-ZnO DNPs containing fibers ( $1 \mathrm{w} \%$ in nylon) exposed to $0.68 \mathrm{~W} / \mathrm{m}^{2}$ irradiation at $50{ }^{\circ} \mathrm{C}$. Changes were measured via the CIE- $L^{*} a^{*} b^{*}$ method. (a) Change in green-red $\left(a^{*}\right)$ and blue-yellow ( $\left.b^{*}\right)$, which correspond to a change in hue; the yellow dots represent alizarin, and the purple dots represent the DNPs, with their labels corresponding to the time at which the data point was obtained in hours. (b, c) Change in lightness $\left(L^{*}\right)$ and distance metric $\Delta E^{*}$ over the course of $200 \mathrm{~h}$, respectively.

531.7 and $531.9 \mathrm{eV}$ for the carbonyl oxygen atoms and zincbound oxygen atoms, respectively. To exclude that this reduction of the 533.6/531.8 intensity ratio was due to a very large signal for $\mathrm{ZnO}$ nanoparticles (which prior to alizarin binding have a measured $\mathrm{O}$ 1s binding energy of $530.7 \mathrm{eV}$ ), we calculated the expected ratio of $\mathrm{ZnO}$-based $\mathrm{O}$ atoms to alizarin-based $\mathrm{O}$ atoms. Based on our TGA data (before and after burning the alizarin off), however, we calculate an $\mathrm{O}$ atom ratio of 1:2.94 for $\mathrm{ZnO}$ to alizarin, i.e., the majority of the $\mathrm{O}$ atoms belongs to alizarin. In addition, if we calculate the binding of $\mathrm{Zn}$ (as $\mathrm{Zn}(\mathrm{OH})_{2}$ complex) to mono-deprotonated alizarin, then the remaining $\mathrm{O}-\mathrm{H}$ oxygen atom displays a markedly different $\mathrm{O}$ 1s energy from all of the other $\mathrm{O}$ atoms, which would not be in line with experiment. As a result, we suggest that the strong reduction of the $\mathrm{O} 1 \mathrm{~s}$ signal in the 533 $\mathrm{eV}$ range was due to the catechol binding of alizarin to the $\mathrm{ZnO}$ surface and the concomitant disappearance of both $\mathrm{C}-$ $\mathrm{OH}$ moieties. This is in line with literature data for experimentally known $\mathrm{O}$ 1s binding energies of metal-bound oxygen atoms (530-532 eV range). ${ }^{53,54}$

UV Exposure Test: Assessment of Exposure of Alizarin DNPs in Nylon Fibers to UV Light. The performance of our alizarin DNPs as a colorant was investigated by processing them into nylon (i.e., polyamide $4,10)$ and exposing the fibers prolonged to UV light. For this, the fibers that contained either alizarin or alizarin DNPs were spun from masterbatches via melt-spinning at $260{ }^{\circ} \mathrm{C}$. These dyed fibers were then exposed to $200 \mathrm{~h}$ of $0.68 \mathrm{~W} / \mathrm{m}^{2}$ radiation with wavelength $300-400 \mathrm{~nm}$, with a maximum emission at $340 \mathrm{~nm}$, at $50{ }^{\circ} \mathrm{C}$. During various time intervals, changes were determined by recording the CIE $L^{*} a^{*} b^{*}$ values ${ }^{55}$ and compared.

The fibers spun from alizarin were yellow, whereas those of the alizarin DNPs were purple. This was also represented by the different CIE $L^{*} a^{*} b^{*}$ values (Figure 8a). Alizarin and the alizarin DNPs had a similar position on the red-green vertical $\left(a^{*}\right)$ axis ( 13.5 vs 13 , respectively) but substantially display significant differences on the blue-yellow horizontal $\left(b^{*}\right)$ axis (13 vs -7 , respectively) (Figure $8 \mathrm{a}$ ). Over the course of $200 \mathrm{~h}$, relatively small changes were observed for the alizarin and
DNPs-dyed fibers on the red-green axis $\left(a^{*}\right)$, and significant changes were detected on the blue-yellow axis $\left(b^{*}\right)$ (Figure $8 \mathrm{a})$; the alizarin-stained fibers turned yellow, whereas the fibers stained with alizarin DNPs retained their color. Similar significant differences were also observed in the lightfastness $\left(L^{*}\right)$ (Figure 8b). Although the alizarin-dyed fibers lost more of their color intensity over the course of $200 \mathrm{~h}\left(\Delta L^{*} 44 \%\right)$, the fibers that were dyed with alizarin DNPs were much less affected $\left(\Delta L^{*} 16 \%\right)$. From these changes in $a^{*}, b^{*}$, and $L^{*}$, the CIE-defined color distance metric $\Delta E^{*}$ value was calculated using eq $1,{ }^{56}$ to indicate the total difference between the two dyed fibers as a result of UV exposure, i.e., before and after treatment.

$$
\begin{aligned}
& \Delta E \\
& \quad *= \\
& \sqrt{\left(\left(L^{*}{ }_{x}-L^{*}{ }_{0}\right)^{2}+\left(a^{*}{ }_{x}-a^{*}{ }_{0}\right)^{2}+\left(b^{*}{ }_{x}-b^{*}{ }_{0}\right)^{2}\right)}
\end{aligned}
$$

Using this formula for the values obtained at different time points resulted in Figure 8c. This graph clearly shows the difference in the amount of change observed in the two differently dyed fibers. For the alizarin dyed fibers, $\Delta E^{*}$ was 15.74, whereas it was 6.06 for the alizarin DNP-dyed fibers. This indicates that this grafting procedure not only greatly improves the lightfastness and thermal stability of the natural dye alizarin but also allows such improvements to be performed in a sustainable method, thereby opening the way for subsequent immobilization studies on a wide range of other natural dyes that, without immobilization, fall short on modern lightfastness and thermal stability standards.

\section{SUMMARY AND CONCLUSIONS}

We developed a method to synthesize alizarin-grafted $\mathrm{ZnO}$ nanoparticles with a high loading $(65 \% \mathrm{w} / \mathrm{w})$ of alizarin. Alizarin was found to be bound to the nanoparticle surface via its catechol moiety in a bidentate manner, as deduced from a combination of detailed IR, ${ }^{1} \mathrm{H}$ NMR, ${ }^{13} \mathrm{C}$ CP-MAS NMR, and XPS measurements. Upon binding to these $\mathrm{ZnO}$ nanoparticles, both the thermal stability and the photostability/lightfastness 
of alizarin increased significantly. This largely expands the options for the application of this natural dye as a colorant in, e.g., polyamide fibers. Finally, in view of the presence of a catechol moiety in a wide range of naturally occurring compounds, including a series of other natural dyes, we anticipate that this type of performance-enhancing immobilization will find wider application, as currently already under study in our laboratories.

\section{ASSOCIATED CONTENT}

\section{SI Supporting Information}

The Supporting Information is available free of charge at https://pubs.acs.org/doi/10.1021/acs.langmuir.0c02981.

IR assignment table, simulated IR spectra, NMR spectra, XPS wide spectra, and simulated XPS spectra of alizarin and alizarin- $\mathrm{ZnO}$ dyed nanoparticles (PDF)

\section{AUTHOR INFORMATION}

\section{Corresponding Authors}

Bauke Albada - Laboratory of Organic Chemistry, Wageningen University \& Research, 6708 WE Wageningen,

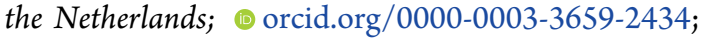
Email: bauke.albada@wur.nl

Han Zuilhof - Laboratory of Organic Chemistry, Wageningen University \& Research, 6708 WE Wageningen, the Netherlands; School of Pharmaceutical Sciences and Technology, Tianjin University, 300072 Tianjin, China; Department of Chemical and Materials Engineering, Faculty of Engineering, King Abdulaziz University, 21589 Jeddah, Saudi Arabia; (1) orcid.org/0000-0001-5773-8506; Email: han.zuilhof@wur.nl

\section{Authors}

Michel P. de Haan - Laboratory of Organic Chemistry, Wageningen University \& Research, 6708 WE Wageningen, the Netherlands; Research Group Biobased Products, Avans University of Applied Sciences, 4818 AJ Breda, the Netherlands; (1) orcid.org/0000-0002-3848-3066

Naveen Balakrishnan - Aachen-Maastricht Institute for Biobased Materials, Maastricht University, 6167 RD Geleen, the Netherlands

Andriy R. Kuzmyn - Laboratory of Organic Chemistry, Wageningen University \& Research, 6708 WE Wageningen, the Netherlands; 1 orcid.org/0000-0002-1571-2911

Guanna Li - Laboratory of Organic Chemistry and Biobased Chemistry and Technology, Wageningen University \& Research, 6708 WE Wageningen, the Netherlands; (1) orcid.org/0000-0003-3031-8119

Hendra M. Willemen - Laboratory of Organic Chemistry, Wageningen University \& Research, 6708 WE Wageningen, the Netherlands

Gunnar Seide - Aachen-Maastricht Institute for Biobased Materials, Maastricht University, 6167 RD Geleen, the Netherlands

Goverdina C. H. Derksen - Research Group Biobased Products, Avans University of Applied Sciences, 4818 AJ Breda, the Netherlands; (0) orcid.org/0000-0003-1718091X

Complete contact information is available at: https://pubs.acs.org/10.1021/acs.langmuir.0c02981

\section{Author Contributions}

The manuscript was written through contributions by all of the authors. All of the authors have given approval to the final version of the manuscript.

Notes

The authors declare no competing financial interest.

\section{ACKNOWLEDGMENTS}

This work is part of the research program RAAK-PRO with project number 02.107, which is (partly) financed by the Dutch Agency for Applied Research (SIA). The authors thank Louis de Smet and Fabian Langensiepen for insightful discussions, and Eric Mattheussens, Barend van Lagen, Sidhu Pujari, and Tatiana Nikolaeva for technical support.

\section{REFERENCES}

(1) Zollinger, H. Color Chemistry: Syntheses, Properties, and Applications of Organic Dyes and Pigments, Wiley: 2003.

(2) Arora, S. Textile Dyes: It's Impact on Environment and Its Treatment. J. Biorem. Biodegrad. 2014, 5, No. 1000e146.

(3) Kant, R. Textile Dyeing Industry an Environmental Hazard. Nat. Sci. 2012, 4, 22-26.

(4) Derksen, G. C. H.; Niederländer, H. A. G.; Van Beek, T. A. Analysis of Anthraquinones in Rubia Tinctorum L. by Liquid Chromatography Coupled with Diode-Array UV and Mass Spectrometric Detection. J. Chromatogr. A 2002, 978, 119-127.

(5) Derksen, G. C. H.; Van Beek, T. A. Rubia Tinctorum L. Stud. Nat. Prod. Chem. 2002, 26, 629-684.

(6) Miliani, C.; Romani, A.; Favaro, G. A. Spectrophotometric and Fluorimetric Study of Some Anthraquinoid and Indigoid Colorants Used in Artistic Paintings. Spectrochim. Acta, Part A 1998, 54, 581588

(7) Puchtler, H.; Meloan, S. N.; Terry, M. S. On the History and Mechanism of Alizarin and Alizarin Red S Stains for Calcium. J. Histochem. Cytochem. 1969, 17, 110-124.

(8) Ovchinnikov, D. Alcian Blue/Alizarin Red Staining of Cartilage and Bone in Mouse. Cold Spring Harbor Protoc. 2009, 4, 5170-5172.

(9) Lee, J. W.; Lee, J. S.; Kang, M.; Su, A. I.; Chang, Y. T. Visual Artificial Tongue for Quantitative Metal-Cation Analysis by an offthe-Shelf Dye Array. Chem. - Eur. J. 2006, 12, 5691-5696.

(10) Mansilla Wettstein, C.; Sánchez, C. G. Characterization of $\mathrm{ZnO}$ as Substrate for DSSC. Phys. Chem. Chem. Phys. 2018, 20, 2191021916.

(11) Gomez, T.; Hermann, G.; Zarate, X.; Pérez-Torres, J. F.; Tremblay, J. C. Imaging the Ultrafast Photoelectron Transfer Process in Alizarin- $\mathrm{TiO}_{2}$. Molecules 2015, 20, 13830-13853.

(12) Huber, R.; Spörlein, S.; Moser, J. E.; Grätzel, M.; Wachtveitl, J. The Role of Surface States in the Ultrafast Photoinduced Electron Transfer from Sensitizing Dye Molecules to Semiconductor Colloids. J. Phys. Chem. B 2000, 104, 8995-9003.

(13) Mech, J.; Grela, M. A.; Szaciłowski, K. Ground and Excited State Properties of Alizarin and Its Isomers. Dyes Pigm. 2014, 103, 202-213.

(14) Lee, S.; Lee, J.; Pang, Y. Excited State Intramolecular Proton Transfer of 1,2-Dihydroxyanthraquinone by Femtosecond Transient Absorption Spectroscopy. Curr. Appl. Phys. 2015, 15, 1492-1499.

(15) Ramakrishna, G.; Singh, A. K.; Palit, D. K.; Ghosh, H. N. Slow Back Electron Transfer in Surface-Modified $\mathrm{TiO}_{2}$ Nanoparticles Sensitized by Alizarin. J. Phys. Chem. B 2004, 108, 1701-1707.

(16) Kaniyankandy, S.; Verma, S.; Mondal, J. A.; Palit, D. K.; Ghosh, H. N. Evidence of Multiple Electron Injection and Slow Back Electron Transfer in Alizarin-Sensitized Ultrasmall $\mathrm{TiO}_{2}$ Particles. J. Phys. Chem. C 2009, 113, 3593-3599.

(17) Matylitsky, V. V.; Lenz, M. O.; Wachtveitl, J. Observation of PH-Dependent Back-Electron-Transfer Dynamics in Alizarin/ $\mathrm{TiO}_{2}$ Adsorbates: Importance of Trap States. J. Phys. Chem. B 2006, 110, $8372-8379$. 
(18) Nawrocka, A.; Krawczyk, S. Electronic Excited State of Alizarin Dye Adsorbed on $\mathrm{TiO}_{2}$ nanoparticles: A Study by Electroabsorption (Stark Effect) Spectroscopy. J. Phys. Chem. C 2008, 112, 1023310241.

(19) Shoute, L. C. T.; Loppnow, G. R. Excited-State Dynamics of Alizarin-Sensitized $\mathrm{TiO}_{2}$ Nanoparticles from Resonance Raman Spectroscopy. J. Chem. Phys. 2002, 117, 842-850.

(20) Sánchez-de-Armas, R.; Oviedo Lo'pez, J.; San-Miguel, M. A.; Sanz, J. F.; Ordejo'n, P.; Pruneda, M. Real-Time TD-DFT Simulations in Dye Sensitized Solar Cells: The Electronic Absorption Spectrum of Alizarin Supported on $\mathrm{TiO}_{2}$ Nanoclusters. J. Chem. Theory Comput. 2010, 6, 2856-2865.

(21) Harikumar, P. S.; Joseph, L.; Dhanya, A. Photocatalytic Degradation of Textile Dyes by Hydrogel Supported Titanium Dioxide Nanoparticles J. Environ. Eng. Ecol. Sci. 2013, 2, DOI: $10.7243 / 2050-1323-2-2$.

(22) Duncan, W. R.; Prezhdo, O. V. Electronic Structure and Spectra of Catechol and Alizarin in the Gas Phase and Attached to Titanium. J. Phys. Chem. B 2005, 109, 365-373.

(23) Agents Classified by the IARC Monographs, Volumes 1102.2011 http://monographs.iarcs.fr/ENG/Classification/ ClassificationsAlphaOrder.pdf. (accessed Oct 9, 2012).

(24) Kocsis, K.; Niedermaier, M.; Kasparek, V.; Bernardi, J.; Redhammer, G.; Bockstedte, M.; Berger, T.; Diwald, O. Langmuir 2019, 35, 8741-8747.

(25) Aditya, A.; Chattopadhyay, S.; Gupta, N.; Alam, S.; Veedu, A. P.; Pal, M.; Singh, A.; Santhiya, D.; Ansari, K. M.; Ganguli, M. ZnO Nanoparticles Modified with an Amphipathic Peptide Show Improved Photoprotection in Skin. ACS Appl. Mater. Interfaces 2019, 11, 56-72. (26) Huang, L.; Zhou, C.; Zhang, Y.; Zhang, S.; Zhang, P. DBHPFunctionalized $\mathrm{ZnO}$ Nanoparticles with Improved Antioxidant Properties as Lubricant Additives. Langmuir 2019, 35, 4342-4352.

(27) Ayodhya, D.; Veerabhadram, G. A Review on Recent Advances in Photodegradation of Dyes Using Doped and Heterojunction Based Semiconductor Metal Sulfide Nanostructures for Environmental Protection. Mater. Today Energy 2018, 9, 83-113.

(28) Hong, R. Y.; Li, J. H.; Chen, L. L.; Liu, D. Q.; Li, H. Z.; Zheng, Y.; Ding, J. Synthesis, Surface Modification and Photocatalytic Property of ZnO Nanoparticles. Powder Technol. 2009, 189, 426-432.

(29) Minga, I.; Kurajica, S.; Mandić, V. Thermal Evolution Process, Properties and Photocatalytic Activity of Sol-Gel Derived Nanocrystalline Anatase in Dye Degradation Process. Acta Graphica 2015, 26, 11-20.

(30) Kansal, S. K.; Lamba, R.; Mehta, S. K.; Umar, A. Photocatalytic Degradation of Alizarin Red S Using Simply Synthesized ZnO Nanoparticles. Mater. Lett. 2013, 106, 385-389.

(31) Bahnemann, D. W.; Kormann, C.; Hoffmann, M. R. Preparation and Characterization of Quantum Size Zinc Oxide: A Detailed Spectroscopic Study. J. Phys. Chem. A 1987, 91, 3789-3798.

(32) Becke, A. D. Density-functional Thermochemistry. III. The Role of Exact Exchange. J. Chem. Phys. 1993, 98, 5648-5652.

(33) Zhao, Y.; Truhlar, D. G. The M06 suite of density functionals for main group thermochemistry, thermochemical kinetics, noncovalent interactions, excited states, and transition elements: two new functionals and systematic testing of four M06-class functionals and 12 other functionals. Theor. Chem. Acc. 2008, 120, 215-241.

(34) Frisch, M. J.; Trucks, G. W.; Schlegel, H. B.; Scuseria, G. E.; Robb, M. A.; Cheeseman, J. R.; Scalmani, G.; Barone, V.; Petersson, G. A.; Nakatsuji, H.. et al.Gaussian 16. Rev. B.01. Rev. B.01. Gaussian Inc.: Wallingford, CT, 2016.

(35) Weigend, F.; Ahlrichs, R. Balanced Basis Sets of Split Valence, Triple Zeta Valence and Quadruple Zeta Valence Quality for $\mathrm{H}$ to Rn: Design and Assessment of Accuracy. Phys. Chem. Chem. Phys. 2005, 7, 3297-3305.

(36) Rappoport, D.; Furche, F. Property-Optimized Gaussian Basis Sets for Molecular Response Calculations. J. Chem. Phys. 2010, 133, No. 134105.
(37) Giesbers, M.; Marcelis, A. T. M.; Zuilhof, H. Simulation of XPS C1s Spectra of Organic Monolayers by Quantum Chemical Methods. Langmuir 2013, 29, 4782-4788.

(38) Zhao, J.; Gao, F.; Pujari, S. P.; Zuilhof, H.; Teplyakov, A. V. Universal Calibration of Computationally Predicted N 1s Binding Energies for Interpretation of XPS Experimental Measurements. Langmuir 2017, 33, 10792-10799.

(39) https://cccbdb.nist.gov/vibscalejust.asp. (accessed Nov 20, 2020).

(40) Cyrański, M. K.; Jamróz, M. H.; Rygula, A.; Dobrowolski, J. C.; Dobrzycki, Ł.; Baranska, M. On Two Alizarin Polymorphs. CrystEngComm 2012, 14, 3667-3676.

(41) Pagliai, M.; Osticioli, I.; Nevin, A.; Siano, S.; Cardini, G.; Schettino, V. DFT Calculations of the IR and Raman Spectra of Anthraquinone Dyes and Lakes. J. Raman Spectrosc. 2018, 49, 668683.

(42) Spanget-Larsen, J.; Christensent, D. H.; Thulstrup, E. W. Symmetry Assignments of Vibrations in 9,10-Anthraquinone Aligned in Stretched Polyethylene. Spectrochim. Acta, Part A 1987, 43, 331335.

(43) Whitney, A. V.; Casadio, F.; Van Duyne, R. P. Identification and Characterization of Artists' Red Dyes and Their Mixtures by Surface-Enhanced Raman Spectroscopy. Appl. Spectrosc. 2007, 61, 994-1000.

(44) Burgio, L.; Clark, R. J. H. Library of FT-Raman Spectra of Pigments, Minerals, Pigment Media and Varnishes, and Supplement to Existing Library of Raman Spectra of Pigments with Visible Excitation. Spectrochim. Acta, Part A 2001, 57, 1491-1521.

(45) Rosi, F.; Paolantoni, M.; Clementi, C.; Doherty, B.; Miliani, C.; Brunetti, B. G.; Sgamellotti, A. Subtracted Shifted Raman Spectroscopy of Organic Dyes and Lakes. J. Raman Spectrosc. 2010, 41, 452458 .

(46) Yang, Y.; Yan, W.; Jing, C. Dynamic Adsorption of Catechol at the Goethite/Aqueous Solution Interface: A Molecular-Scale Study. Langmuir 2012, 28, 14588-14597.

(47) Hermans, J. J.; Keune, K.; Van Loon, A.; Iedema, P. D. An Infrared Spectroscopic Study of the Nature of Zinc Carboxylates in Oil Paintings. J. Anal. At. Spectrom. 2015, 30, 1600-1608.

(48) Biesta, W.; van Lagen, B.; Gevaert, V. S.; Marcelis, A. T. M.; Paulusse, J. M. J.; Nielen, M. W. F.; Zuilhof, H. Preparation, Characterization, and Surface Modification of Trifluorethyl EsterTerminated Silicon Nanoparticles. Chem. Mater. 2012, 24, 43114318.

(49) Wang, L.-Q.; Exarhos, G. J.; Windisch, C. F., Jr. Probing hydrogen in $\mathrm{ZnO}$ nanorodes using solid-state ${ }^{1} \mathrm{H}$ nuclear magnetic resonance. Appl. Phys. Lett. 2007, 90, No. 173115.

(50) Ali, M.; Donakowski, M. D.; Mayer, C.; Winterer, M. Chemical vapor functionalization: a continuous production process for functionalized $\mathrm{ZnO}$ nanoparticles. J. Nanopart. Res. 2012, 14, No. 689.

(51) Carrasco, E.; Oujja, N.; Sanz, M.; Marco, J. F.; Castillejo, M. Xray and ion irradiation effects on azurite, malachite and alizarin pictorial models. Microchem. J. 2018, 137, 381.

(52) Gardella, J. A.; Ferguson, S. A.; Chin, R. L. $\pi^{*} \leftarrow \pi$ Shakeup Satellites for the Analysis of Structure and Bonding in Aromatic Polymers by X-Ray Photoelectron Spectroscopy. Appl. Spectrosc. 1986, 40, 224-232.

(53) Syres, K. L.; Thomas, A. G.; Flavell, W. R.; Spencer, B. F.; Bondino, F.; Malvestuto, M.; Preobrajenski, A.; Grätzel, M. Adsorbate-Induced Modification of Surface Electronic Structure: Pyrocatechol Adsorption on the Anatase $\mathrm{TiO}_{2}(101)$ and Rutile $\mathrm{TiO}_{2}$ (110) Surfaces. J. Phys. Chem. C 2012, 116, 23515-23525.

(54) McNeill, A. R.; Bell, K. J.; Hyndman, A. R.; Gazoni, R. M.; Reeves, R. J.; Downard, A. J.; Allen, M. W. Synchrotron X-Ray Photoelectron Spectroscopy Study of Electronic Changes at the $\mathrm{ZnO}$ Surface Following Aryldiazonium Ion Grafting: A Metal-to-Insulator Transition. J. Phys. Chem. C 2018, 122, 12681-12693.

(55) Goodman, T. M. International Standards For Colour. In Colour Design - Theories and Applications, Oxford/Cambridge/etc; Best, J., Ed.; Woodhead Publishing/The Textile Institute: 2012; pp 177-218. 
(56) Luo, M. R. CIELAB BT - Encyclopedia of Color Science and Technology, Luo, R., Ed.; Springer Berlin Heidelberg: Berlin, Heidelberg, 2015. 